\title{
NILAI KENUSANTARAAN ARSITEKTUR BOLA UGI MENURUT SANRO BOLA DI DUSUN KAJUARA KABUPATEN BONE
}

\author{
Hamka \\ Jurusan Arsitektur, Fakultas Teknik Sipil dan Perencanaan, Institut Teknologi Nasional Malang, \\ J1. Bendungan Sigura-Gura No. 2, Malang \\ Email: hamka07@lecturer.itn.ac.id
}

\begin{abstract}
Abstrak
Arsitektur Nusantara dipahami sebagai arsitektur rakyat Nusantara yang berada pada lokalitas ruang budaya, memiliki pengetahuan tersembunyi (tacit knowledge) terkait tradisi, nilai, makna kesemestaan dan kesetempatan (Pangarsa, 2006). Karakteristik budaya arsitektur Nusantara yang berada di wilayah Indonesia memiliki wujud yang beragam, baik secara fisik maupun non fisik. Salah satu arsitektur rakyat yang berada di wilayah ruang budaya Nusantara adalah arsitektur bola ugi (rumah Suku Bugis). Bola ugi ini memiliki unsur-unsur kenusantaraan terkait dengan nilainilai dan makna ruang dan fisiknya. Tujuan penelitian ini adalah untuk mengetahui nilai-nilai kenusantaraan yang terkandung di dalam bola ugi yang berada di Dusun Kajuara, berdasarkan pengetahuan yang dimiliki oleh ahli bangunan rumah bugis yakni sanro bola. Metodologi penelitian menggunakan metode kualitatif analisis deskriptif berdasarkan hasil wawancara dari beberapa sanro bola yang dilakukan secara snow ball sampling. Hasil penelitian menunjukkan bahwa nilai kenusantaraan yang terdapat pada bola ugi menurut sanro bola, meliputi unsur hirarki ruang, tata letak ruang, orientasi, dan simbol struktur.
\end{abstract}

Kata kunci: arsitektur Nusantara, arsitektur tradisional, rumah tradisional Bugis

\begin{abstract}
Title: Nusantara Value of Architecture of Bola Ugi at Kajuara Village, Bone District, According to Sanro Bola

Nusantara Architecture has been apprehended as an archipelagic vernacular architecture located in the locality of cultural space. It has a tacit knowled related to traditions, values, as well as a universal and sectional significance (Pangarsa, 2006). The cultural characteristics of Nusantara architecture in Indonesia has a diverse forms, both physical and non-physical. One of archipelagic vernacular architectures in the cultural space is bola ugi architecture (Buginese House). Bola ugi has archipelagic elements associated with the values and space and physical significance. The purpose of this study was to determine the archipelagic values in bola ugi based on the knowledge possessed by the House of Bugis architect sanro bola. This research used a descriptive analysis qualitative research methodologies based on interviews of some sanro bolas and was conducted using a snow ball sampling. The results of the research showed that the archipelagic value of bola ugi included the hierarchical elements of space, room layout, orientation, and the symbol of the structure.
\end{abstract}

Keywords: Nusantara architecture, traditional architecture, Bugis traditional house 


\section{Pendahuluan}

Secara sederhana bola ugi merupakan sebutan untuk rumah tradisional Suku Bugis yang berfungsi sebagai tempat tinggal atau hunian bagi golongan masyarakat biasa. Dari segi arti kata "bola" berarti rumah dan "ugi" berarti Bugis, sehingga secara keseluruhan diartikan sebagai rumah Bugis. Ditinjau dari segi sosial masyarakat, Suku Bugis memiliki sistem tingkatan sosial atau strata sosial, yaitu golongan bangsawan (anakarung), rakyat biasa (to maradeka atau to sama), dan hamba sahaya (ata). Berdasarkan pada tingkatan sosial masyarakat Suku Bugis tersebut, maka rumah Bugis digolongkan dalam beberapa jenis, yaitu: (a) Sao-raja, rumah untuk keluarga bangsawan, memiliki bubungan atau timpa laja bersusun tiga atau lebih, (b) Sao-piti, bentuknya lebih kecil dari sao raja, dan memiliki bubungan atau timpa laja yang bersusun dua, dan (c) Bola, merupakan rumah bagi masyarakat umumnya/rakyat biasa (to sama), (Hasan dan Prabowo, 2002).

Bola ugi merupakan produk budaya tradisional yang merupakan hasil karya sanro bola melalui proses perenungan dengan menghubungkan antara alam semesta dan sang pencipta, yang hasilnya berupa sebuah pengetahuan tersembunyi. Sanro bola dalam hal ini dipahami sebagai orang yang mengerti tentang tradisi nilai dan makna, tata cara, aturan-aturan yang terdapat pada wujud bola ugi. Keikutsertaan peran sanro bola dalam pembangunan bola ugi dilakukan dengan tujuan untuk mencari bentuk keselarasan hidup antara manusia dengan alam, antara manusia dengan sesama, dan antara manusia dengan pencipta-Nya (Beddu, 2009). Nilai kenusantaraan pada lokalitas arsitektur rakyat yang terdapat di wilayah Nusantara khususnya Indonesia menampilkan wujud kebhinekaan. Nilai kenusantaraan dalam arsitektur Nusantara secara garis besar dapat dipahami sebagai nilai yang memiliki nilai kesemestaan, kemanusiaan, dan ketuhanan, sebagaimana nilai-nilai tersebut banyak ditemukan pada elemenelemen/unsur bangunan atau rumah tradisional yang tersebar di wilayah Nusantara.

Penerapan nilai kenusantaraan dapat dilihat pada beberapa konsep arsitektur tradisional yang ada di Indonesia seperti: (a) Hirarki sumbu vertikal bahwa rumah dianggap sebagai bentuk mikrokosmos dari alam raya yaitu dunia atas, tengah, dan bawah, (Mashuri, 2012), (b) Skala dan proporsi tubuh manusia, contohnya di Jawa menjadikan manusia sebagai ukuran benda (protagoras), sedangkan benda-benda dan alat-alat memakai ukuran yang sesuai dengan badan manusia untuk menjelaskan ukuran ruang rumah tradisionalnya (Frick, 2001), (c) Arah orientasi bahwa arsitektur tradisional tidak lahir begitu saja, namun sarat dengan filsafat, nilai tradisi, dan kepercayaan, seperti arah dan letak permukiman dan rumah terkait dengan faktor keberuntungan dan keselamatan penghuni rumah. Penentuan arah ini menjadi sangat penting bahkan disakralkan dan hal yang menjadi patokan biasanya adalah gunung, matahari, laut, dan kiblat (Idawarni, 2011), dan (d) Simbol struktur, pada arsitektur tradisional merupakan elemen pembentuk ruang yang mengandung nilai dan makna. Contohnya pada rumah joglo, konstruksi bangunan yang khas dengan fungsi setiap bagian yang berbeda satu sama lain yang mengandung unsur 
filosofis terkait nilai dan makna, seperti struktur tiang penyangga utama (saka guru) yang berjumlah empat membentuk formasi persegi, (Djono, Utomo dan Subyantoro, 2012).

Fokus penelitian mengenai nilai kenusantaraan yang akan dikaji dalam tulisan ini adalah pengetahuan sanro bola terkait nilai kenusantaraan yang terdapat pada elemen/unsur arsitektur bola ugi yang terdapat di wilayah Dusun Kajuara, dan penelitian ini merupakan penelitian yang orisinil sesuai waktu dan lokasinya.

\section{Metode}

Penelitian ini menggunakan metode kualitatif deskriptif analisis, dengan melakukan wawancara langsung ke key person yaitu sanro bola dengan teknik snow ball sampling. Berdasarkan pada studi lapangan ditemukan 3 (tiga) orang sanro bola hingga seluruh data yang dibutuhkan terpenuhi dan seluruh data yang terkumpul menjadi jenuh. Key person pertama yang ditemui adalah Puang Nusi (60 thn), selanjutnya diarahkan ke Puang Miri (78 Thn), dan kemudian terakhir ke Dg. Mannippi (80 Thn). Keseluruhan data yang terkumpul kemudian dikumpulkan, diidentifikasi, dan dianalisis, selanjutnya dirangkum menjadi satu kesatuan pengetahuan mengenai nilai kenusantaraan yang terdapat pada bola ugi yang berada di wilayah Dusun Kajuara, Kabupaten Bone, Sulawesi Selatan.

\section{Hasil dan Pembahasan}

\section{Hirarki Ruang}

Hirarki ruang bola ugi di Dusun Kajuara ini dibagi secara vertikal dan horisontal yang masing-masing terdiri dari tiga bagian. Ruang vertikal, yaitu bagian bawah (subola), bagian tengah (watangmpola), dan bagian atas (rakkeang), sedangkan ruang horisontal, yaitu bagian depan (legolego), bagian tengah/dalam (lalengmpola), dan bagian belakang (annasung) (Gambar 1).

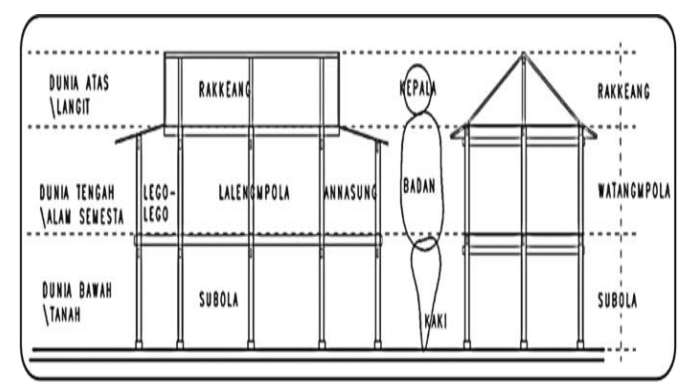

Hirarki vertikal

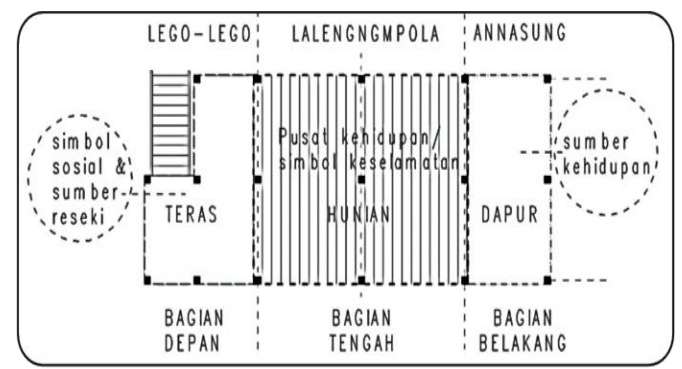

Hirarki horisontal

Gambar 1. Hirarki ruang vertikal dan horisontal

Sumber: Hamka, 2015

Hirarki ruang secara vertikal dianggap sebagai bentuk makro kosmos dari alam semesta yaitu, dunia bawah (bawah tanah) sebagai subola, dunia tengah (alam semesta) sebagai watangmpola, dan dunia atas (langit) sebagai rakkeang. Pembagian hirarki ruang vertikal ini juga dianalogikan sebagai manusia yang memiliki kaki (subola), badan (watangmpola), dan kepala (rakkeang).

Hirarki ruang vertikal memiliki fungsi sebagai berikut: bagian bawah (subola) memiliki beberapa macam fungsi, tergantung pada latar belakang pemilik rumah. Beberapa diantaranya difungsikan sebagai tempat hewan 
ternak, tempat penyimpanan kayu bakar, peralatan bertani, gudang, tempat kerja, dan ada juga yang menggunakan sebagai tempat istirahat. Bagian tengah (watangmpola) berfungsi sebagai hunian, dan bagian atas (rakkeang) berfungsi sebagai tempat menyimpan hasil panen khususnya padi dan barang rumah tangga lainnya. Posisi pembagian ketiga dunia tertata dalam bentuk bersusun tiga, yang menempatkan dunia kehidupan berada ditengahtengah yang diapit oleh dunia atas dan dunia bawah. Agar dunia atas dan dunia bawah dapat memberikan kemakmuran bagi dunia tengah, maka manusia yang menghuni dunia tersebut harus tunduk dan patuh terhadap tatanan yang ada dalam dunia makrokosmos.

Pembagian fungsi pada hirarki ruang horisontal pada bagian watangmpola dibagi menjadi tiga fungsi utama yaitu, bagian depan (lego-lego) merupakan area publik yang bersifat sosial untuk menerima tamu yang tidak berkepentingan khusus, tempat berkumpul atau sekedar bersantai bersama. Bagian tengah atau dalam (lalengmpola) merupakan area utama yang posisinya sangat penting karena menjadi pusat kehidupan di dalam rumah yang ditandai dengan adanya tiang alliri yang diposisikan sebagai posi bola yang berarti pusat rumah. Di dalam lalengmpola ini terdapat ruang tamu bagi tamu jauh atau dengan tujuan tertentu, ruang keluarga, dan kamar tidur. Bagian belakang (annasung) atau rumah dapur yang berfungsi sebagai area service yang dianggap sebagai penopang kehidupan seperti memasak, tempat makan, dan area pencucian (teme-temeng). Meskipun posisi bola annasung ini berada di bagian belakang, ruangan ini memiliki posisi penting karena paling sering digunakan. Bahkan tetangga yang berkunjung langsung menuju ke dapur dan bersosialisasi di area ini, hal tersebut merupakan salah satu budaya masyarakat yang sudah menjadi kebiasaan sehari-hari masyarakat di Dusun Kajuara.

Dari pandangan kosmologi pembagian ruang horisontal ini dipercaya bahwa bagian depan merupakan arah datangnya rezeki/simbol sosial, bagian tengah sebagai pusat kehidupan/keselamatan yang harus dilindungi sehingga berada ditengah, dan bagian belakang dianggap sebagai penopang kehidupan.

Hirarki ruang bola ugi secara vertikal lebih kepada perwujudan hubungan antara manusia dengan ketuhanan yang menunjukkan tingkatan hirarki ruang bola ugi dalam tiga lapis dunia yaitu dunia bawah (subola), dunia tengah (watangmpola), dan dunia atas (rakkeang). Hirarki ruang horisontal merupakan perwujudan hubungan sosial kemanusiaan yang terbagi menjadi tiga bagian, yaitu bagian depan (lego-lego), tengah (lalengmpola), dan belakang (bola annasung). Posisi watangmpola secara vertikal dan lalengmpola secara horisontal merupakan ruang terpenting yang berada di tengah karena merupakan pusat kehidupan yang sesungguhnya, yakni dunia alam semesta sebagai tempat hunian dalam pandangan mikrokosmos. Maka dunia tengah ini akan ditopang dan dilindungi oleh dunia bawah dan dunia atas secara vertikal, serta bagian depan dan bagian belakang secara horisontal. Sehingga dari nilai tingkatan kepentingan ruang dalam sistem hirarkinya menempatkan bagian tengah sebagai pusat yang paling penting dibanding fungsi ruang yang lainnya. 


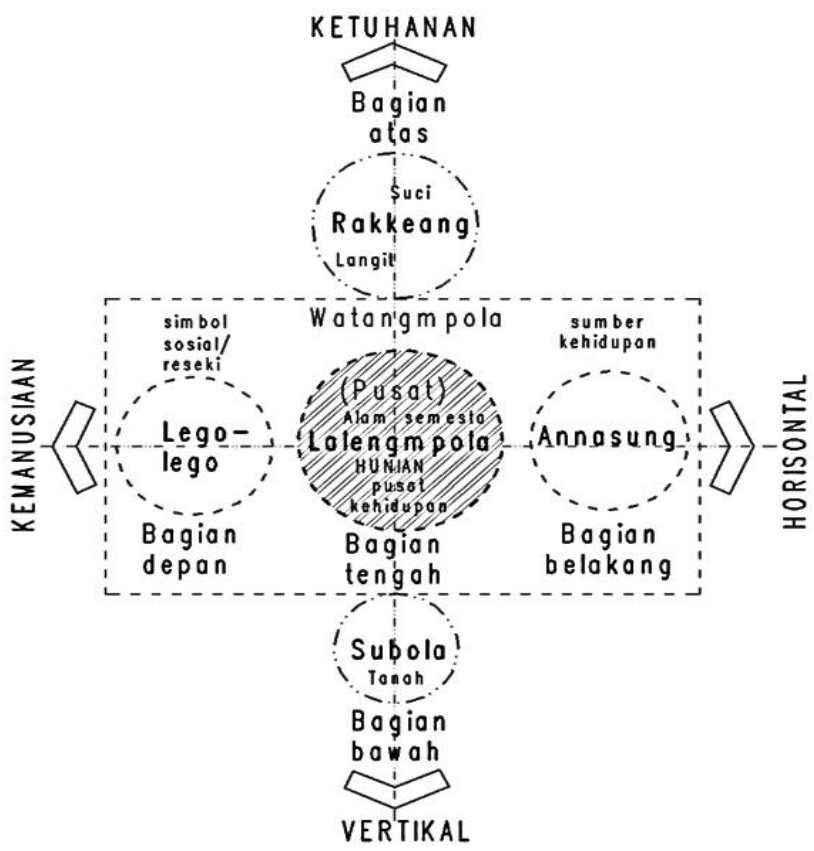

Gambar 2. Nilai Hirarki ruang vertikal dan horisontal

Sumber: Hamka, 2015

Nilai kenusantaraan yang terdapat pada hirarki ruang bola ugi di Dusun Kajuara terwujud dalam nilai Ketuhanan secara vertikal dan nilai kemanusiaan secara horisontal, (Gambar 2).

\section{Tata Letak Ruang}

Tata letak ruang-ruang yang terdapat pada hunian dari segi aturan menyesuaikan dengan peruntukan fungsi hirarki ruang bola ugi secara horisontal. Pembagian fungsi pada hirarki ruang horisontal pada bagian watangmpola dibagi menjadi tiga fungsi utama, yaitu bagian depan (lego-lego) merupakan area publik yang bersifat sosial untuk menerima tamu yang tidak berkepentingan khusus, tempat berkumpul atau sekedar bersantai bersama. Bagian tengah atau dalam (lalengmpola) terdapat ruang tamu bagi tamu jauh atau dengan tujuan tertentu, ruang keluarga, dan kamar tidur. Bagian belakang (annasung) atau rumah dapur yang berfungsi sebagai area service yang dianggap sebagai penopang kehidupan seperti, memasak, tempat makan, dan area pencucian (teme-temeng).

Tata letak ruang yang terdapat pada bagian watangmpola secara umum terfokus pada letak kamar tidur sebagai acuan utama. Letak kedua ruang secara umum dipengaruhi oleh arah orientasi rumah itu sendiri atau secara aturan letak kamar tidur yang baik harus berada di sebelah Barat atau Selatan. Hal ini terkait dengan posisi kepala saat tidur harus berada di sebelah Barat atau Selatan. Jadi, rumah yang menghadap ke Timur atau Barat letak kamar tidurnya berada di sebelah Selatan dan rumah yang menghadap ke Utara atau Selatan letak kamar tidurnya berada di Barat. Kamar tidur mempertimbangkan posisi kepala saat tidur (Barat dan Selatan) terhadap orientasi mata angin, yaitu Barat: menerima matahari dari Timur (rezeki), Timur: pamali tidur dengan posisi kaki berada di Barat (Kabbah), Utara: tidak boleh tidur seperti posisi orang mati, dan Selatan: bentuk tolak bala (Gambar 3). 


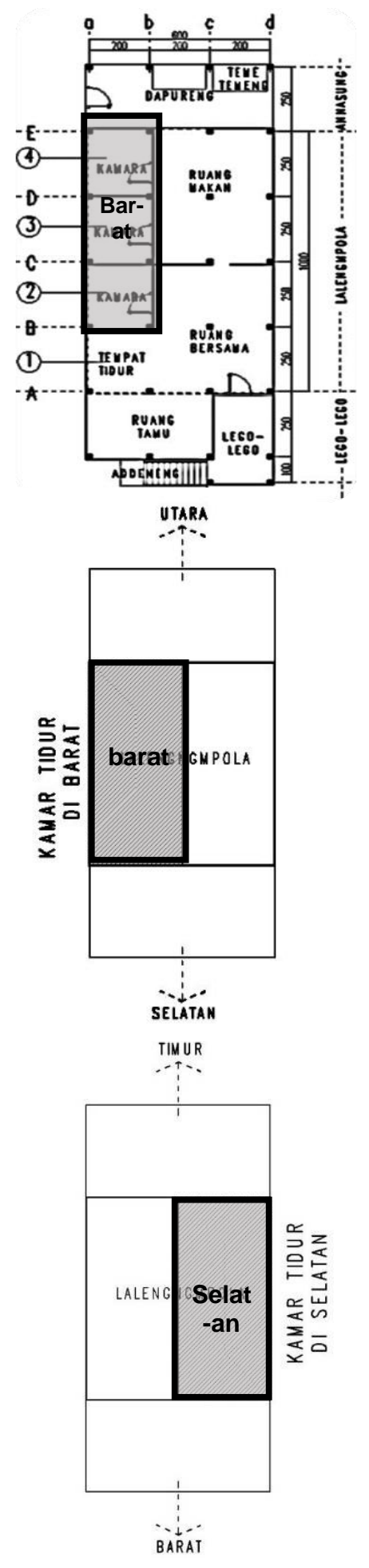

Gambar 3. Tata letak kamar tidur (kamara) berdasarkan orientasi rumah Sumber: Hamka, 2015

Tata letak kamar tidur juga mempertimbangkan aspek-aspek berikut: (a) Kamar tidur rumah yang berada pada topografi perbukitan biasanya akan mempertimbangkan letak mikrokosmosnya, yaitu letak kamar tidur akan berada pada sisi tanah yang lebih tinggi, karena manusia yang memiliki kepala harus menempatkannya pada posisi yang lebih tinggi pula. (b) Letak kamar untuk laki-laki berada di depan dan perempuan di bagian belakang, hal tersebut merupakan bentuk simbol perlindungan terhadap keluarga. (c) Posisi letak kamar tidur sifatnya lebih fleksibel, bisa berada di sisi kanan atau kiri watangmpola, ataupun di kedua sisinya bagi rumah yang memiliki tambahan luasan spasial lebih ke samping. Hal tersebut tergantung pada pertimbangan aturan-aturan kepercayaan adat yang ada, serta kebutuhan dan keinginan dari pemilik rumah.

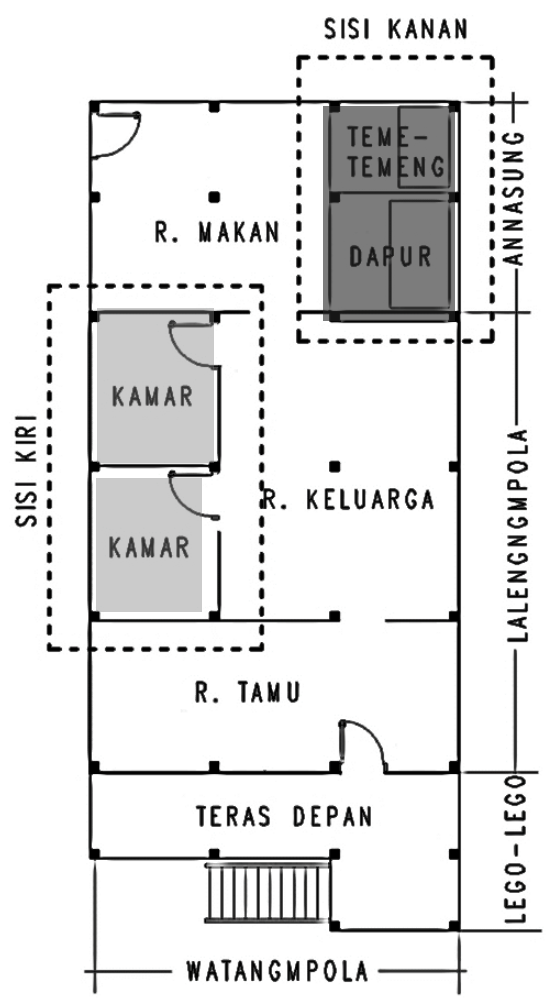

Gambar 4. Tata letak dapureng dan temetemeng

Sumber: Hamka, 2015 
Letak dapureng dan teme-temeng berada di belakang pada bagian annasung, letaknya berada pada sisi yang berbeda dengan letak kamar tidur. Jika kamar tidur berada pada di sisi kiri maka letak dapureng dan temetemeng berada di sisi kanan bagian annasung (Gambar 4).

Bagian subola fungsinya lebih beragam, tergantung pada latar belakang sosial pemilik rumah. Secara umum tata letak ruang pada bagian bawah (subola) ini dibagi menjadi tiga bagian, yaitu bagian depan dibawah lego-lego berfungsi sebagai ruang terbuka yang dapat digunakan untuk beristirahat, bermain, bekerja, menjemur pakaian dan yang lainnya. Bagian tengah di bawah lalengmpola berfungsi sebagai gudang untuk menyimpan barang-barang pertanian dan yang lainnya. Sedangkan bagian belakang khususnya yang berada di bawah bola annasung umumnya difungsikan sebagai tempat hewan ternak seperti kandang ayam atau kandang sapi, seperti pada (Gambar 5).

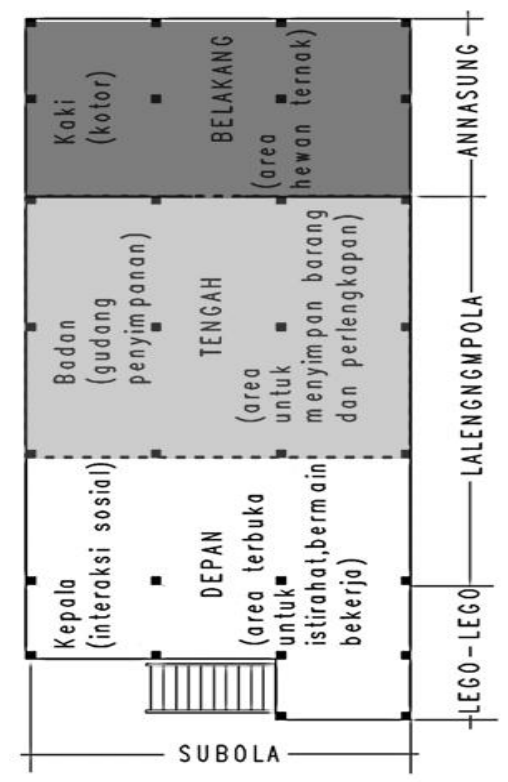

Gambar 5. Tata letak ruang pada bagian subola (kolong rumah)

Sumber: Hamka, 2015
Tata letak ruang yang ada pada bola ugi di Dusun Kajuara ini sifatnya lebih fleksibel dengan pertimbangan utama pada kepercayaan terhadap orientasi posisi tidur terhadap penjuru mata angin dan letaknya terhadap kondisi topografi lingkungannya. Pembagian tata letak spasial terkait dengan sifat dan fungsi berdasarkan sosial budaya masyarakat, sehingga pola tata letak antara rumah satu dengan yang lainnya bisa saja berbeda. Nilai kenusantaraan yang terdapat pada pola tata letak ruang bola ugi memiliki nilai hubungan kemanusiaan sebagai bentuk aktualisasi hubungan sosial masyarakat, dan nilai kesemestaan serta ketuhanan terkait dengan kepercayaan dalam menentukan letak ruang-ruang tertentu.

\section{Orientasi}

Secara umum bola ugi dapat berorientasi ke empat penjuru mata angin, yaitu Timur, Barat, Utara dan Selatan. Namun orientasi rumah terbaik dan dianjurkan menghadap ke arah Timur dan Barat. Orientasi Timur merupakan arah terbitnya matahari, dalam hal ini rumah yang berorientasi ke Timur akan memiliki rezeki yang melimpah, sedangkan orientasi ke Barat merupakan arah kiblat menuju Kabbah. Rumah yang beorientasi ke Barat dipercaya akan mendatangkan kesalamatan dunia akhirat. Orientasi rumah yang berada perbukitan dianjurkan berorientasi ke arah perbukitan atau tanah yang lebih tinggi, karena secara pandangan kosmologi pegunungan dianggap sebagai dunia atas/bagian kepala (tempat baik dan suci). Selain itu, gunung merupakan tempat masyarakat di dusun ini mencari nafkah sebagai petani, sehingga hal tersebut menjadi bentuk penghargaan terhadap pegunungan yang telah menjadi 
sumber kehidupan. Maka orientasi rumah yang berada diperbukitan akan menghadap ke arah tanah yang lebih tinggi, sehingga rumah dapat menghadap ke arah Timur, Barat, Utara, atau Selatan. Rumah yang berada pada kondisi tanah yang datar akan mempertimbangkan orientasi Timur dan Barat (Gambar 6).

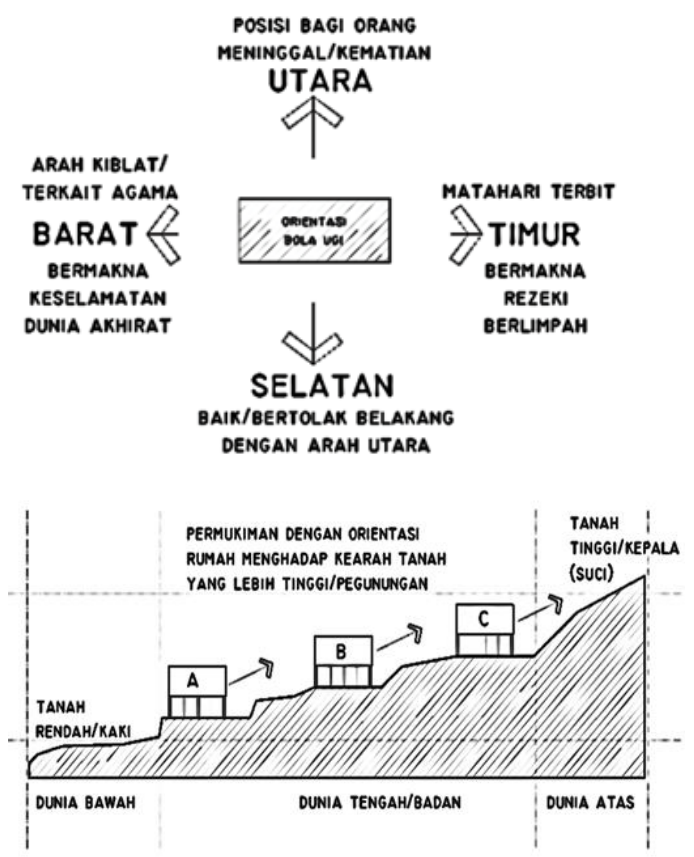

Gambar 6. Kepercayaan orientasi bola ugi di Dusun Kajuara

Sumber: Hamka, 2015

Gambar 6 merupakan anjuran arah orientasi yang dianggap baik, namun orientasi bola ugi yang ada di Dusun Kajuara menunjukkan pola orientasi rumah yang beragam, hal ini berdasarkan pada pertimbanganpertimbangan tertentu seperti: kondisi eksisting lingkungan yang spesifik terkait mitos sehingga menghindari arah tertentu, hubungan kekeluargaan yang berorientasi ke rumah orang tua sebagai bentuk penghormatan, dan pertimbangan kemudahan sirkulasi sehingga berorientasi langsung menghadap ke sirkulasi jalan utama.
Orientasi ruang-ruang yang terdapat di dalam spasial hunian tidak terdapat aturan khusus mengenai orientasinya, kecuali arah orientasi dapureng (dapur) yang tidak boleh berhadapan langsung dengan arah pintu masuk dari depan atau searah dengan orientasi rumah. Sebab saat orang memasak akan membelakangi pintu masuk, hal tersebut dianggap menolak rezeki yang datang. Orientasi dapureng ini akan menyesuaikan dengan arah orientasi rumah. Apabila rumah menghadap ke Timur atau Barat, maka dapureng sebaiknya menghadap ke Utara atau Selatan, dan apabila rumah menghadap ke Utara atau Selatan, maka sebaiknya dapureng menghadap ke Timur atau Barat. Contoh gambaran arah orientasi dapur yang dianjurkan pada rumah yang menghadap ke Selatan (Gambar 7).

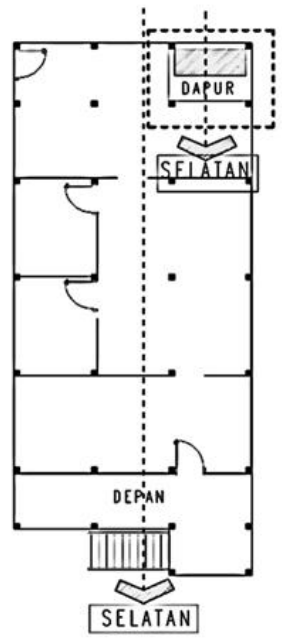

Tidak dianjurkan

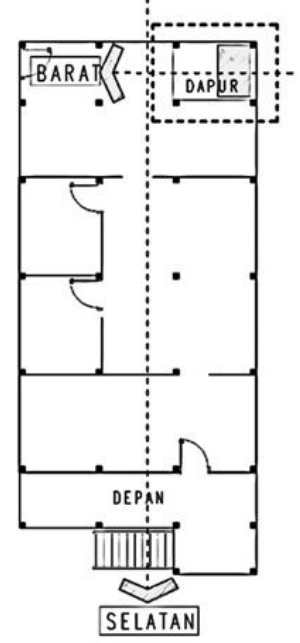

Dianjurkan
Gambar 7. Penentuan orientasi dapur (dapureng)

Sumber: Hamka, 2015

\section{Simbol Struktur}

Sama seperti rumah Bugis di daerah lainnya dan beberapa rumah-rumah rakyat Nusantara lainnya yang berada di wilayah Nusantara Indonesia, bola ugi yang ada di Dusun Kajuara ini juga memiliki simbol struktur vertikal yang 
disucikan atau disakralkan, yaitu posi bola. Posi bola ini merupakan pusat rumah yang dijadikan simbol ketuhanan untuk memohon keselamatan oleh pemilik rumah, sehingga tata letaknya berada pada bagian depan di dekat pintu masuk. Posi bola ini memiliki pasangan, yaitu petuona posi bola, jarak diantara kedua alliri (tiang/kolom kayu) ini memiliki fungsi penyaring hal-hal buruk yang ikut dari luar rumah. Kedua alliri ini sangat penting, sehingga dalam proses pendiriannya terdapat beberapa ritual dan aturan-aturan yang harus dijalankan agar tidak mendatangkan hal-hal yang buruk bagi penghuni rumah. Tata letak posi bola utama dan petuona posi bola keseluruhan objek terletak pada baris kedua tiang alliri ke belakang. Terdapat beberapa pola tata letak kedua tiang alliri tersebut berdasarkan jumlah tiang alliri objek ke samping (berjumlah ganjil atau genap) (Gambar 8).

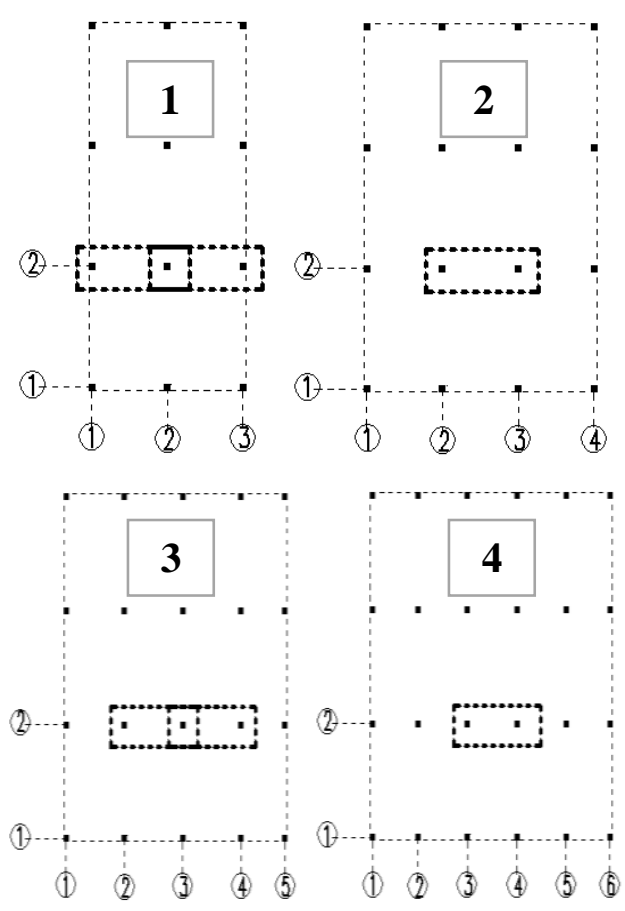

Gambar 8. Tata letak posi bola dan petuona posi bola

Sumber: Hamka, 2015
Bola ugi yang memiliki 3 baris dan dan 5 baris tiang alliri ke samping (1 dan 3) maka posi bola terletak pada bagian tengah dan petuona dapat memilih salah satu tiang alliri yang berada di sampingnya. Sedangkan yang memiliki 4 dan 6 baris tiang alliri ke samping ( 2 dan 4) maka letak posi bola dan petuona berada pada dua tiang alliri yang berada di bagian tengah. Simbol struktur vertikal ini merupakan simbol hubungan manusia dengan sang pencipta, sedangkan struktur horisontal yang mengikat tiang-tiang alliri berupa sistem pasak kayu merupakan simbol hubungan kemanusiaan.

\section{Kesimpulan}

Nilai kenusantaraan bola ugi di Dusun Kajuara menunjukkan bahwa secara hirarki ruang dibedakan menjadi dua, yaitu hirarki vertikal terdiri dari bagian bawah (subola), tengah (watangmpola), dan atas (rakkeang), sedangkan hirarki horizontal utama terdapat dibagian tengah (watangmpola) pada ruang vertikal yang dibagi menjadi tiga bagian, yaitu bagian depan (lego-lego), dalam (lalengmpola), dan belakang (bola annasung). Tata letak ruang pada hunian terfokus pada letak kamar tidur (kamara). Letak kamar tidur berada di sebelah Barat jika rumah menghadap ke Utara atau Selatan dan terletak di sebelah Selatan jika rumah menghadap ke Timur atau Barat. Orientasi bola ugi menghadap ke arah tanah yang lebih tinggi jika berada pada kondisi tanah yang berkontur, arah orientasi yang baik menghadap ke Timur atau Barat, namun secara umum orientasi dapat mengarah ke empat penjuru angin. Dari segi struktur terdapat inti simbol struktur, yaitu posi bola dan petuona posi bola sebagai simbol keselamatan. 
Nilai kenusantaraan tersebut secara keseluruhan dipengaruhi oleh unsur kepercayaan atau mitologi. Hal tersebut menunjukkan nilai-nilai kesemestaan dan kesetempatan arsitektur bola ugi di Dusun Kajuara sebagai bagian dari arsitektur rakyat Nusantara. Nilai yang terkandung di dalamnya berasal dari pandangan mitologi masyarakat mengenai kepercayaan terhadap aturan adat yang ada. Kepercayaan tersebut telah ditanamkan pada bola ugi semenjak dari proses perencanaan, pembangunan, dan pasca pembangunan melalui aturan-aturan adat masyarakat setempat. Secara pengetahuan, bola ugi memiliki konsep dan aturannya sendiri berdasarkan pada hasil wawancara key person/sanro bola. Namun karakter, latar belakang sosial, kebutuhan, dan keinginan dari masing-masing penghuni rumah berbeda-beda. Sehingga hal tersebut perlu dikaji untuk mengetahui terapan pengetahuan nilai kenusantaraan tersebut pada beberapa objek bola ugi yang terdapat di Dusun Kajuara, agar dapat diketahui sejauh mana pengetahuan tersembunyi (tacit knowledge) tersebut diterapkan.

\section{Daftar Pustaka}

Beddu. (2009). Arsitek arsitektur tradisional Bugis. Jurnal Penelitian Enjiniring. Vol. 12, No. 2 Tahun 2009 Hal: 190198.

Djono, Utomo \& Subyantoro. (2012). Nilai kearifan lokal rumah tradisional Jawa. Humaniora, Vol. 24 No. 3 Oktober 2012 Hal. 269-278.

Frick, H. (2001). Pola struktural dan teknik bangunan di Indonesia. Kanisius: Yogyakarta.
Hasan \& Prabowo. (2002). Perubahan bentuk dan fungsi arsitektur tradisional Bugis di kawasan pesisir Kamal Muara, Jakarta Utara. International symposium 'building research and the sustainability of the built environment in the tropics, Universitas Tarumanegara.

Idawarni. (2011). Penentuan arah dan letak permukiman dan rumah tinggal kaitannya dengan kosmologi, studi kasus: Kampung Kanarea, Kecamatan Bajeng Gowa Sulawesi Selatan. Local Wisdom-Jurnal Ilmiah Online, ISSN: 20863764. Volume: III, Nomor: 1, Hal: 09-18.

Mashuri. (2012). Perwujudan kosmologi pada bangunan tradisional Toraja. LANTING Journal of Architecture, Volume 1, Nomor 1, Februari 2012, Hal 1-10.

Pangarsa, G.W. (2016). Merah putih arsitektur Nusantara. Yogyakarta: Andi Offset. 